\title{
Acute Renal Failure Following Hypokalemic Rhabdomyolysis due to Chronic Glycyrrhizic Acid Administration
}

\author{
Akihiko Chubachi, Hideki Wakui, Ken-ichi Asakura, Shigeki Nishimura, Yasushi Nakamoto* \\ and Akira B MiurA*
}

\begin{abstract}
A 72-year-old man developed acute renal failure (ARF) following severe hypokalemic rhabdomyolysis. The hypokalemia was due to chronic glycyrrhizin (glycyrrhizic acid) administration. Although glycyrrhizin-induced hypokalemic rhabdomyolysis has been occasionally reported, the association of this type of rhabdomyolysis with ARF has not been described. In the present case, there was a sensitivity to glycyrrhizin the preceding renal insufficiency, and dehydration which was thought to have contributed to ARF. It should be recognized that elderly patients with such predisposing factors may be susceptible to a rapid deterioration of renal function after glycyrrhizin-induced hypokalemic rhabdomyolysis.
\end{abstract}

(Internal Medicine 31: 708-711, 1992)

Key words: glycyrrhizin, hypokalemia, myoglobinuric renal failure

\section{Introduction}

Hypokalemia is a known complication of chronic administration of glycyrrhizin (glycyrrhizic acid), which has mineralocorticoid-like effects and causes hypertension, hypernatremia and decreased plasma concentrations of renin and aldosterone $(1,2)$. Although glycyrrhizininduced hypokalemia may cause occasionally severe rhabdomyolysis, the complication of acute renal failure (ARF) derived from the rhabdomyolysis is extremely rare. This is consistent with the possibility that the mineralocorticoid-like actions of glycyrrhizin cause sodium retention and volume expansion, and thereby prevent the decrease in the glomerular filtration rate and the development of ARF (3). Nevertheless, we report an elderly patient who developed ARF following hypokalemic rhabdomyolysis due to chronic glycyrrhizin administration.

\section{Case Report}

A 72-year-old male was admitted in December 26, 1989 with the complaint of convulsion and delirium. The patient had been treated with glycyrrhizin-containing antacid (glycyrrhizin $90 \mathrm{mg}$ daily) from 1988, with an added daily dose of glycyrrhizin ( $150 \mathrm{mg}$ daily) since
February 1989. There was a three-year history of chronic renal insufficiency, and the creatinine clearance was $46 \mathrm{ml} / \mathrm{min}$ in December 1988.

In mid-December 1989 , the patient complained of anorexia and general malaise. Five days prior to entry, he consulted his physician, who found hypertension and edema, and prescribed furosemide. At that time, his serum potassium was $1.4 \mathrm{mEq} / 1$, serum creatinine $1.8 \mathrm{mg} / \mathrm{dl}$, glutamic-oxaloacetic transaminase (GOT) $450 \mathrm{U} / 1$, glutamic-pyruvic transaminase (GPT) $235 \mathrm{U} / 1$. Three days before admission, the patient noticed muscle weakness which made him unable to stand up, and on the same day this was followed by a decrease of urine volume and an appearance of dark brown urine. On December 26, the patient experienced generalized seizures and on the same day, he was transferred to our hospital.

The temperature was $38.5^{\circ} \mathrm{C}$, blood pressure was $102 / 70 \mathrm{mmHg}$, and respirations were 24 . On physical examination the patient's skin was dry and markedly dehydrated, and his consciousness was delirious. $\mathrm{He}$ suffered from frequent tonic-clonic seizures. Blood urea nitrogen (BUN) was $95.3 \mathrm{mg} / \mathrm{dl}$, serum creatinine was $9.5 \mathrm{mg} / \mathrm{dl}$, and uric acid was $19.0 \mathrm{mg} / \mathrm{dl}$. Serum concentration of potassium $(\mathrm{K})$ was $1.9 \mathrm{mEq} / \mathrm{l}$, sodium $(\mathrm{Na})$ $128 \mathrm{mEq} / 1$, chloride (Cl) $64 \mathrm{mEq} / 1$, and calcium (Ca)

From the Department of Internal Medicine, Yuri Kumiai General Hospital, Honjo, and * the Third Department of Internal Medicine, Akita University School of Medicine, Akita

Received for publication October 7, 1991; Accepted for publication January 17, 1992

Reprint requests should be addressed to Dr. Akihiko Chubachi, the Third Department of Internal Medicine, Akita University School of Medicine, 1-1-1 Hondo, Akita 010, Japan 


\section{Rhabdomyolysis and ARF from Glycyrrhizin}

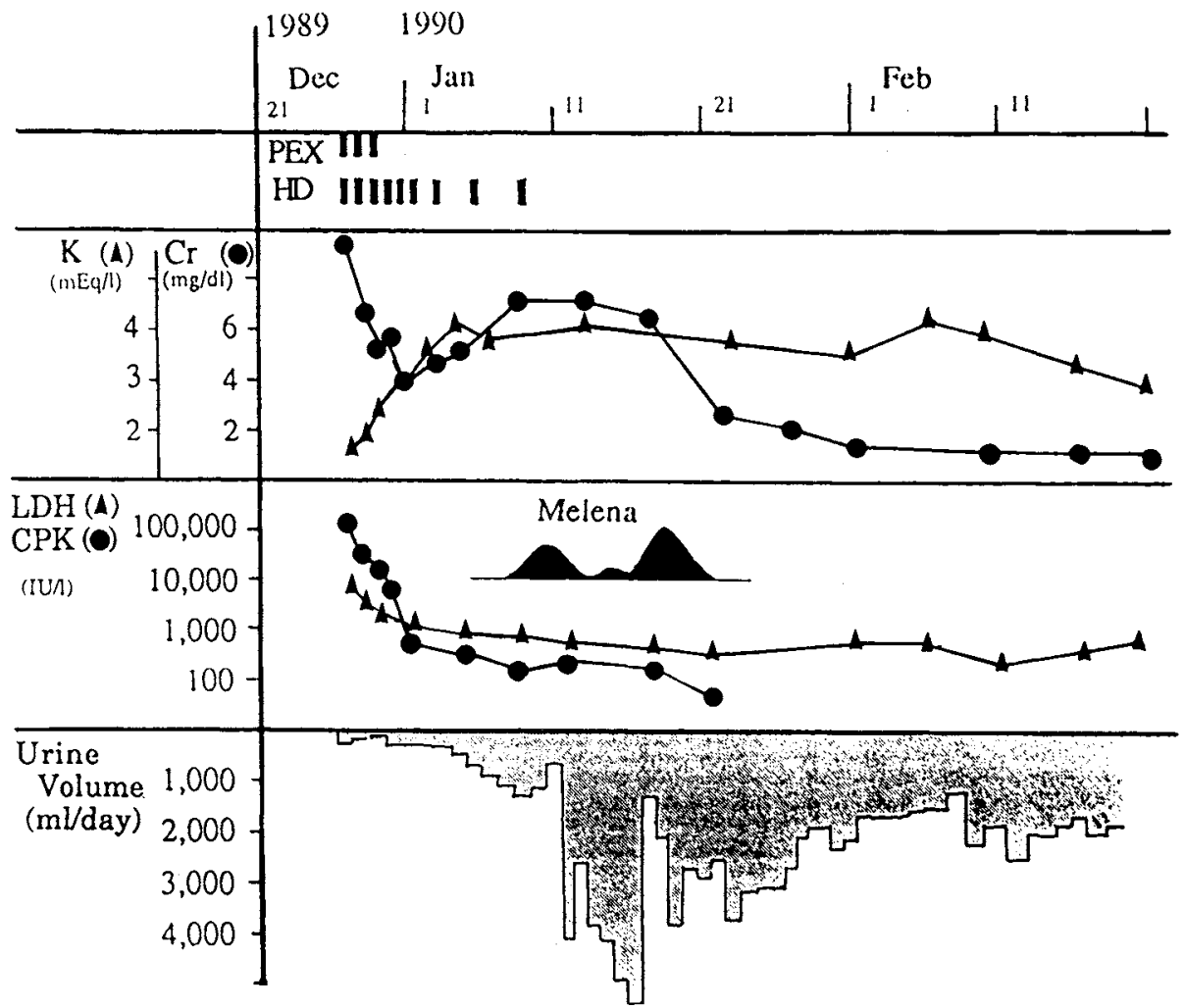

Fig. 1. Clinical Course. CPK: creatine phosphokinase, $\mathrm{Cr}$ : serum creatinine, HD: hemodialysis, K: serum potassium, LDH: lactate dehydrogenase, PEX: plasma exchange.

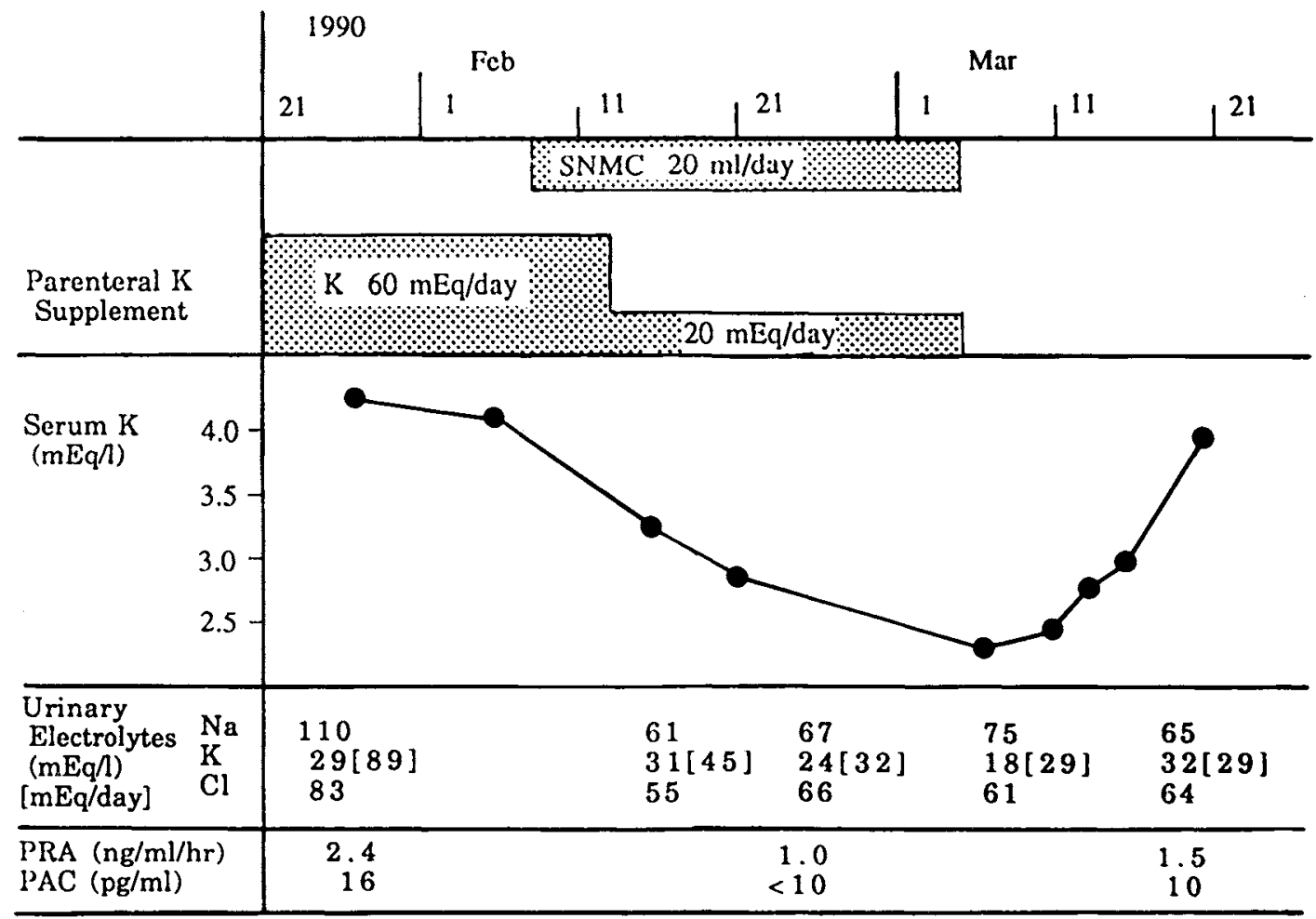

Fig. 2. Changes in serum and urinary potassium, plasma levels of renin activity and aldosterone before, during and after the re-administration of glycyrrhizin. $\mathrm{Cl}$ : chloride, $\mathrm{K}$ : potassium, Na: sodium, PAC: plasma aldosterone concentration, PRA: plasma renin activity, SNMC: Stronger Neo-Minophagen $C^{\circledR}$ (glycyrrhizic acid preparation available in Japan). 


\section{Chubachi et al}

$6.8 \mathrm{mg} / \mathrm{dl}$. Serum creatine phosphokinase $(\mathrm{CPK})$ was $112,700 \mathrm{U} / 1$, lactate dehydrogenase $(\mathrm{LDH}) 8,270 \mathrm{U} / 1$, GOT $860 \mathrm{U} / \mathrm{l}$, GPT $335 \mathrm{U} / \mathrm{l}$, serum myoglobin $111,300 \mathrm{ng} /$ $\mathrm{ml}$. The urine was dark brown with a $\mathrm{Na}$ concentration of $57 \mathrm{mEq} / 1$, and $\mathrm{K}$ concentration of $14 \mathrm{mEq} / \mathrm{l}$. An arterial blood gas showed $\mathrm{pH}$ of $7.52, \mathrm{PaO}_{2} 55.5 \mathrm{mmHg}$, $\mathrm{PaCO}_{2} 49.5 \mathrm{mmHg}$, and base excess $15.0 \mathrm{mEq} / \mathrm{l}$. Plasma renin activity (PRA) and plasma aldosterone concentration (PAC) were $1.6 \mathrm{ng} / \mathrm{ml} / \mathrm{h}$ and $91 \mathrm{pg} / \mathrm{ml}$, respectively. An electrocardiogram showed a high $P$ wave in limb leads and prominent $U$ wave.

The patient was immediately treated with plasma exchange and hemodialysis (Fig. 1). He received $350 \mathrm{mEq}$ of potassium via a central venous line during the first three days. On the 8 th hospital day, serum potassium returned to normal $(3.6 \mathrm{mEq} / \mathrm{l})$, and serum $\mathrm{LDH}$ and CPK fell to $1,329 \mathrm{U} / 1$ and $694 \mathrm{U} / 1$, respectively. The patient suddenly passed massive bloody stool, and subsequently developed hypovolemic shock on the 14th hospital day. Although hemodialysis was discontinued on that day because of intermittent melena and hypotension, serum creatinine gradually returned to the baseline level, and it was $1.5 \mathrm{mg} / \mathrm{dl}$ on the 38th hospital day. With respect to massive melena, mesenteric angiographic examinations and a computed tomographic scan of the abdomen gave negative results.

As the hepatic enzymes had elevated gradually, a glycyrrhizin preparation, $40 \mathrm{mg}$ daily, was administered intravenously with extreme care, from the 44th to the 69th day in hospital (Fig. 2). During this period, his serum potassium decreased gradually to $2.3 \mathrm{mEq} / 1$, although the daily urinary excretion of potassium did not exceed $50 \mathrm{mEq} /$ day. At the same time, rhabdomyolysis was not observed. Serum potassium level increased to normal two weeks after the cessation of glycyrrhizin preparation. Although PRA and PAC were within the normal range before the administration of glycyrrhizin, they were $1.0 \mathrm{ng} / \mathrm{ml} / \mathrm{h}$ and below $10 \mathrm{pg} / \mathrm{ml}$, respectively, two weeks later. Thereafter, serum potassium and sodium have remained within normal range, although the potassium has not been supplemented.

\section{Discussion}

We report a patient with hypokalemic rhabdomyolysis complicated by ARF. There seems to be little doubt that in the present case, glycyrrhizin was mainly responsible for the severe hypokalemia in spite of the low dose of glycyrrhizin $(240 \mathrm{mg} /$ day). Although hypokalemia and hypertension usually result from chronic ingestion of $1 \mathrm{mg}$ or more daily of glycyrrhizin in Western countries $(1-5)$, there have been several Japanese reports that smaller doses of glycyrrhizin (20-250 mg per day) could have produced severe hypokalemic rhabdomyolysis $(6-10)$. Kuriyama et al (6) described a patient who developed marked hypokalemia due to chronic adminis- tration of glycyrrhizin ( $150 \mathrm{mg}$ daily) and speculated that an extreme sensitivity to glycyrrhizin might be related to the occurrence of hypokalemia in their patient. In the present case, we also prescribed a very small dose of glycyrrhizin, $40 \mathrm{mg}$ per day, after the patient's serum potassium and creatinine had recovered to his baseline levels. One month later, the patient developed moderate hypokalemia and a definite depression of the reninaldosterone axis, although rhabdomyolysis did not develop. These values returned to normal in a short period after discontinuation of glycyrrhizin. Recently, several reports have claimed that glycyrrhizin induces hypermineralocorticoidism by inhibiting $11 \beta$-hydroxysteroid dehydrogenase and then producing a high level of cortisol, which binds to and activates mineralocorticoid receptors in the kidney $(11,12)$. Furthermore, there is now evidence that $11 \beta$-hydroxysteroid dehydrogenase deficiency may occur in a number of common clinical situations including chronic renal failure. Accordingly, $11 \beta$-hydroxysteroid dehydrogenase deficiency can partly explain the sensitivity to glycyrrhizin in the present patient.

The most striking feature in the present case is the development of ARF following hypokalemic rhabdomyolysis. Although ARF is not rare in patients with rhabdomyolysis [its incidence ranges from $16.5 \%$ to $67 \%$ in a reported series $(13,14)$, and glycyrrhizin-induced hypokalemia sometimes evokes rhabdomyolysis, the complication of ARF in glycyrrhizin-induced hypokalemic rhabdomyolysis has not been reported previously $(1-10)$. With regard to the mechanism of protection against ARF, Heidemann and Kreuzfelder (3) described that sodium retention and volume expansion via the mineralocorticoid-like action of glycyrrhizin might be protective against the development of ARF in hypokalemic rhabdomyolysis.

In the present case, several factors seem to participate in the occurrence of ARF. First, the serum creatinine had been mildly elevated for three years, although the urinalysis was negative. The long-standing hypokalemia might have evoked tubulointerstitial nephritis (15), and might have consequently caused the chronic renal insufficiency in this patient. Ward (13) reported that a previous renal disease is not predictive of the development of ARF in patients with rhabdomyolysis. However, he defined a previous renal disease by clinical history alone, and it is still possible that a decreased renal function prior to rhabdomyolysis may be responsible for the development of ARF in the setting of rhabdomyolysis. Secondly the present patient had been severely dehydrated prior to admission. Multiple factors including long-standing anorexia, fever, and diuretics may have additively contributed to this patient's dehydration. In fact, Ward (13) described the dehydration at presentaiton as one of the most predictive factors of ARF in rhabdomyolysis. Kageyama (14) indicated that plasma volume 
contraction might be responsible for the development of ARF in patiens with rhabdomyolysis. Furthermore, experimental studies on animal models of rhabdomyolysis have emphasized the importance of dehydration in predisposing ARF $(16,17)$. Thirdly, the present patient experienced recurrent generalized seizures on the day of admission, and these seizures may have further precipitated the pre-existing rhabdomyolysis due to hypokalemia (18).

In conclusion, the present case demonstrates the possibility that ARF could develop even in patients with hypokalemic rhabdomyolysis due to chronic glycyrrhizin administration. Although Heidemann and Kreuzfelder (3) emphasized that the mineralocorticoid-like action of glycyrrhizin might be protective against the development of ARF in hypokalemic rhabdomyolysis, we suppose that this mechanism could not be fully effective in severely dehydrated patients. It is important to recognize that glycyrrhizin-induced hypokalemic rhabdomyolysis could result in ARF, especially in elderly patients who have a decreased renal function and are susceptible to dehydrating conditions.

Acknowledgments: We wish to thank Seiki Shimizu, MD, of the Department of Urology for his kind help in performing hemodialysis.

\section{References}

1) Conn JW, Rovner DR, Cohen EL. Licorice-induced pseudoaldosteronism, hypertension, hypokalemia, aldosteropenia and suppressed plasma renin activity. J Am Med Assoc 205: 492, 1968.

2) Montero F. Exogenous mineralocorticoid-like disorders. Clin Endocrinol Metab 10: 465, 1981.

3) Heidemann HT, Kreuzfelder E. Hypokalemic rhabdomyolysis with myoglobinuria due to the licorice ingestion and diuretic treatment. Klin Wochenschr 61: 303, 1983.
4) Nielsen I, Pederson RS. Life-threatening hypokalemia caused by liquorice ingestion. Lancet 2: 1305, 1984.

5) Ashar KN, Abduo TJ, Menon NK. Severe hypokalemic rhabdomyolysis due to ingestion of liquorice during Ramadan. Aust NZ J Med 19: 365, 1989.

6) Kuriyama $Y$, Takano $T$, Okada F, Nukada T. Hypersensitivity to glycyrrhizin; A case report. Med J Osaka Univ 26: 75, 1975.

7) Sugimoto $K$, Shionoiri $H$, Inoue $K$, Kaneko $Y$. A case report of hypokalemic myopathy due to ingestion of large coses of "Jintan". Nihon Naika Gakkai Zasshi 73: 66, 1984 (in Japanese).

8) Okada K, Kobayashi S, Tsunematsu T. A case of Sjögren's syndrome associated with hypokalemic myopathy due to glycyrrhizin. Nihon Naika Gakkai Zasshi 76: 744, 1987 (in Japanese).

9) Fujimori $Y$, Okamoto $S$, Tsujii $T$, et al. Three cases of pseudoaldosteronism due to methanol extracts of licorice (FM-100). J Jpn Soc Int Med 76: 855, 1987 (in Japanese).

10) Taira K, Aoi W, Hazama M, Chiyoda S, Mukai H. Pseudoaldosteronism with hypokalemic myopathy due to Neo-Umor (glycyrrhizin). Nihon Naika Gakkai Zasshi 77: 1284, 1988 (in Japanese).

11) Farese RV Jr, Biglieri EG, Shackleton CHL, Irony I, GomezFontes R. Liquorice-induced hypermineralocorticoidism. N Engl J Med 325: 1223, 1991.

12) Walker BR, Edwards CRW. 11ß-hydroxysteroid dehydrogenase and enzyme-mediated receptor protection: life after licorice? Clin Endocrinol 35: 281, 1991.

13) Ward MM. Factors predictive of acute renal failure in rhabdomyolysis. Arch Intern Med 148: 1553, 1988.

14) Kageyama Y. Rhabdomyolysis: clinical analysis of 20 patients. Jpn J Nephrol 31: 1099, 1989.

15) Riemenschneider TH, Bohle A. Morphologic aspects of lowpotassium and low-sodium nephropathy. Clin Nephrol 19: 271, 1983.

16) Bidani AK, Churchill PC. Na intake, renal renin, and the severity of myohemoglobinuric renal failure in rats. Am J Physiol 241: F34, 1981

17) Garcia G, Snider T, Feldman, Clyne DH. Nephrotoxicity of myoglobin in the rat: Relative importance of urine $\mathrm{pH}$ and prior dehydration (Abstract). Kidney Int 19: 200, 1981.

18) Eiser AR, Neff MS, Slifkin RF. Acute myoglobinuric renal failure: A consequence of the neuroleptic malignant syndrome. Arch Intern Med 142: 601, 1982. 